\title{
"Macho como um touro": pedagogias culturais de masculinidades em duas versões da história de Ferdinando, o touro
}

"Male like a bull": cultural pedagogies of masculinity in two versions of the story of Ferdinando, the bull

\author{
João Paulo Baliscei \\ Professor doutor na Universidade Estadual de Maringá, Maringá, Paraná, Brasil. \\ vjbaliste@gmail.com - http://orcid.org/0000-0001-8752-244X \\ Laiana Moraes Azevedo \\ Professora na Escola Municipal Nadyr Maria Alegretti, Maringá, Paraná Brasil. \\ laiana.ma@hotmail.com - https://orcid.org/0000-0002-9449-9070 \\ Geiva Carolina Calsa \\ Professora doutora na Universidade Estadual de Maringá, Maringá, Paraná, Brasil. \\ gccalsa@hotmail.com - http://orcid.org/0000-0003-2581-2948
}

Recebido em 28 de novembro de 2018

Aprovado em 27 de agosto de 2019

Publicado em 13 de maio de 2020

\section{RESUMO}

O objetivo desse artigo é identificar e analisar as distintas pedagogias culturais sobre masculinidades, oferecidas em filmes de animação direcionados aos sujeitos infantis. Para tal, selecionaram-se duas versões da história do touro Ferdinando, uma de 1938 e outra de 2017, produzidas por estúdios que atualmente pertencem a Disney. As análises, elaboradas a partir dos Estudos das Masculinidades (BADINTER, 1993; CONNELL, 1995; 1997; 2016; KIMMEL, 1998) e do conceito de Pedagogias Culturais (DEPORTE, 2016; DEPORTE E COSTA, 2017), sublinham a hegemonia, cumplicidade, subordinação e resistência como traços das relações de poder que envolvem as construções de gênero. Nas análises, consideramos que, apesar das pressões exercidas pelos demais personagens para que Ferdinando se espelhe em identidades de gênero hegemônicas, nas duas narrativas fílmicas, de maneiras distintas entre si, o protagonista transgride com aquilo que lhe é esperado enquanto "macho" e também enquanto "touro".

Palavras-chave: Estudos das Masculinidades; Gênero; Educação. 


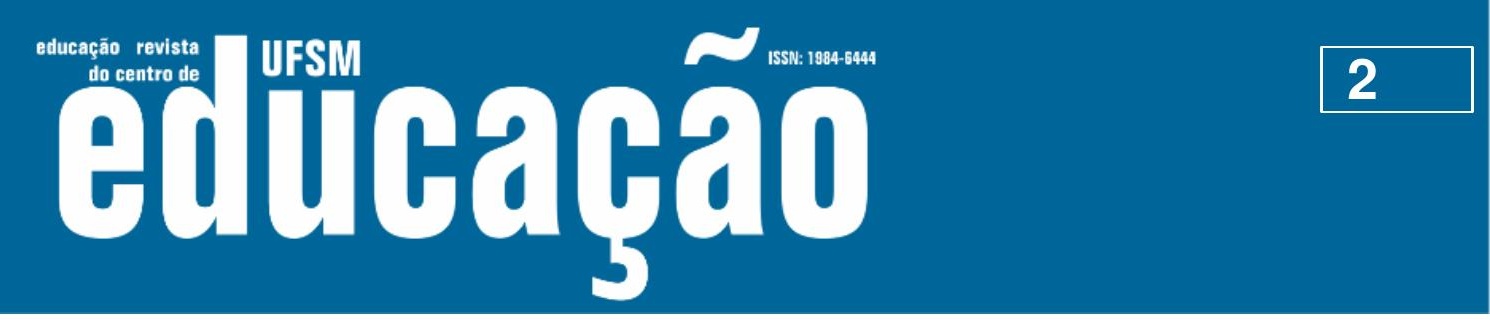

ISSN: 1984-6444 | http://dx.doi.org/10.5902/1984644435815

\begin{abstract}
The aim of this paper is to identify and analyze the different cultural pedagogies about masculinities, offered in animated films directed to children subjects. For this, were selected two versions of the story of the bull Ferdinando, one from 1938 and one from 2017 , produced by studios that currently belong to Disney. The analyzes, elaborated from the Masculinities Studies (BADINTER, 1993; CONNELL, 1995; 1997; 2016; KIMMEL, 1998), and from concept of Cultural Pedagogies (DEPORTE, 2016; DEPORTE E COSTA, 2017) emphasize hegemony, complicity, subordination and resistance as traces of the relations of power that surround the constructions of gender. In the analysis, we considered that, despite the pressure exerted by the other characters for Ferdinando to imitate hegemonic gender identities, in both filmic narratives, in different ways, the protagonist transgresses with what is expected of him as "male" and also as "bull."
\end{abstract}

Keywords: Masculinities Studies; Genre; Education; Disney.

\title{
Introdução: Estudos Culturais e as Pedagogias Culturais
}

A tecnologia tem avançado muito nas últimas décadas, intensificando a divulgação e alcance das imagens para todas as idades. Podemos supor que, em condições contemporâneas, uma criança na primeira infância, possivelmente, já obteve contato com mais imagens do que seus/suas antepassados/as tiveram no decorrer de toda sua existência, em razão da globalização e do ritmo a partir do qual as informações circulam pelo mundo. Sobre isso, Lisandra Gomes ${ }^{1}$ (2008) observa que,

\begin{abstract}
antes mesmo de participar dos espaços coletivos de educação, as crianças já se relacionaram com outros adultos [...] assim como já perceberam e compararam as imagens e os textos que circulam pela mídia. Isso significa que, antes de participarem dos espaços da infância, as crianças já tiveram contato com o rádio, com o cinema, com as imagens nas revistas e nos jornais e, principalmente, com a televisão, pois os meios de comunicação fazem parte da cultura na qual estão inseridas. (GOMES, 2008, p. 188, grifos da autora).
\end{abstract}

Em concomitância com a crescente relação entre infâncias e tecnologias digitais, em especial, entre aquelas que perpassam os textos midiáticos para os quais a autora chama a atenção, fazem-se necessários estudos sobre as formas como a cultura contribui na formação dos significados que constituem as identidades culturais de meninos e meninas em idade escolar. A respeito disso, destacamos os Estudos 


\section{Autตaดูão}

ISSN: 1984-6444 | http://dx.doi.org/10.5902/1984644435815

Culturais como campo de investigação que busca problematizar as concepções contemporâneas sobre as identidades culturais. As reflexões propostas por Stuart Hall (2006; 2012; 2016), por exemplo, destacam que as identidades pós-modernas têm assinalado intensas e significativas transformações em relação às identidades de sociedades modernas. Diferentes dos sujeitos de outros tempos e espaços, aqueles/as que (con)vivem em uma sociedade pós-moderna - alicerçada na velocidade, no imediatismo, no prazer, na descartabilidade e no consumo -, conforme o autor, apresentam identidades fragmentadas, indefinidas, provisórias, complexas e sobrepostas, tecidas por atributos individuais e coletivos.

Ainda sobre isso, Hall (2006, p. 12) argumenta que a identidade cultural pósmoderna se assemelha à uma "celebração-móvel: formada e transformada continuamente em relação às formas pelas quais somos representados ou interpelados". Disso, podemos extrair que para a concepção pós-moderna, a constituição da identidade cultural está mais relacionada aos sistemas de representação e às identificações feitas ao longo da vida do que aos fenômenos biológicos e inatos. Para o autor, as identificações implicam o emprego dos artefatos culturais, tais como as imagens cinematográficas e publicitárias, para a constituição,

não daquilo que nós somos, mas daquilo no qual nos tornamos. Têm a ver não tanto com as questões "quem nós somos" ou "de onde nós viemos", mas muito mais com questões "quem nós podemos nos tornar", "como nós temos sido representados" e "como essa representação afeta a forma como nós podemos representar a nós próprios". (HALL, 2012, p. 109).

A preocupação que os Estudos Culturais têm com as maneiras como os textos e imagens sugerem identidades culturais específicas para grupos específicos aparece, por exemplo, em outro estudo de Hall (2016) em que o autor problematiza as maneiras como os negros e negras têm sido representados em visualidades constituídas pela publicidade, esporte, arte, cinema e medicina. Denomina como Regime de Representação o repertório de imagens a partir do qual a diferença - neste caso, a negritude - é representada. Representar é, nessa abordagem cultural, o "processo pelo qual os significados são produzidos e compartilhados entre os 


\section{Autharẫ}

ISSN: 1984-6444 | http://dx.doi.org/10.5902/1984644435815

membros de uma cultura. Representar envolve o uso da linguagem, de signos e imagens que significam ou representam objetos" (HALL, 2016, p. 31, grifo nosso). Compreende-se, pois, que os significados não são fixos e tampouco naturais às sociedades, mas sim que são construídos e legitimados pelos regimes de representação - logo, também podem ser questionados e modificados.

Quando os Estudos Culturais foram instituídos, em 1964, pelo Birmingham Center for Contemporary Cultural Studies (CCCS), na Inglaterra, as discussões foram realizadas a partir do contexto social de jovens da periferia e de grupos operários, enfatizando temáticas como racismo e hegemonia cultural. Pela característica que os Estudos Culturais têm de acolher os infames, logo passaram a contemplar outros sujeitos socialmente marginalizados. Assim, outras identidades culturais - tais como as de gênero e de sexualidade - passaram a também fazer parte da gama de assuntos contemplados por esse campo de investigação, sobretudo, a partir do conceito de Pedagogias Culturais.

Segundo Paula Deporte de Andrade e Marisa Vorraber Costa (2017), o termo Pedagogia Cultural está presente nas produções acadêmicas há aproximadamente duas décadas, sendo um meio que contribuiu para a visibilidade dos Estudos Culturais em pesquisas brasileiras. Para as autoras, o conceito em questão tem possibilitado certa maximização dos campos e objetos de estudos em educação, pois se desenvolveu na articulação entre pedagogia e cultura. Considera que a escola não é o único espaço que oportuniza e efetiva situações de ensino. O conceito de pedagogias culturais contempla, portanto, que para além das instituições escolares, as imagens publicitárias, televisivas, cinematográficas e outras expressões da cultura popular produzem aprendizagens. Em outro estudo, Andrade (2016) traça um histórico desse conceito e observa que, antes da expressão pedagogias culturais, outras duas - Pedagogia Popular e Tecnologias Culturais - já haviam sido utilizadas para se referir à produção de significados e à regulação de identidades conferidas aos artefatos culturais, porém, suas limitações acarretaram em seu desuso por parte dos e das estudiosas culturais. O conceito de pedagogias culturais, ainda segundo a autora, é compartilhado não apenas pelos Estudos Culturais como por outras áreas, tais como 


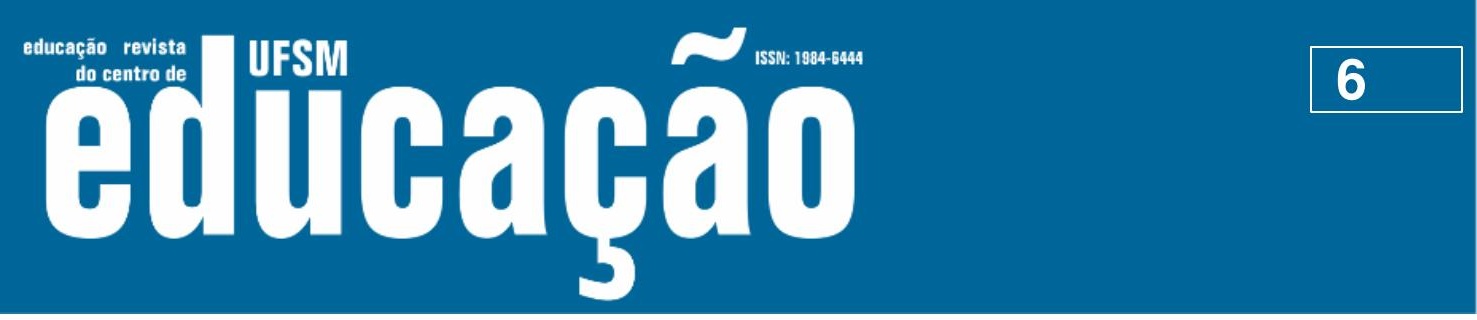

ISSN: 1984-6444 | http://dx.doi.org/10.5902/1984644435815

os aprendizados sobre modos de existência, sobre modos de comportar-se, sobre modos de constituir a si mesmo - para os diferentes grupos sociais, particularmente para as populações mais jovens - se fazem com a contribuição inegável dos meios de comunicação. Estes não constituiriam apenas uma das fontes básicas de informação e lazer: trata-se bem mais de um lugar extremamente poderoso no que tange à produção e à circulação de uma série de valores, concepções, representações-relacionadas a um aprendizado cotidiano sobre quem nós somos, o que devemos fazer com nosso corpo. (FISCHER, 2002, p. 153).

Compreendendo a necessidade de teorizar os elementos apresentados pelos filmes infantis, o conceito de pedagogias culturais nos auxilia a problematiza a relação que os sujeitos constroem com aquilo que veem, sem considerá-los como meros "receptores" das informações implícitas nas mensagens fílmicas, mas como agentes dessas identificações. Buscamos, portando, analisar como o ato de ver filmes - e interagir com seus personagens e imagens - contribui para a (des)construção das identidades culturais dos/as expectadores/as.

Nesse sentido, adotamos o conceito de pedagogias culturais como ferramenta de análise fílmica por compreendermos que é também por meio deste e de outros artefatos culturais que as visões sociais e individuais são construídas e que as identidades culturais são produzidas.

Quais significados acerca de masculinidades são produzidos, ensinados e compartilhados por filmes de animação? Diante desse problema de pesquisa, desenvolvemos este artigo com o objetivo de identificar e analisar as distintas pedagogias culturais sobre masculinidades, oferecidas em filmes de animação direcionados aos sujeitos infantis. Para tal, selecionamos como objeto de análise duas versões da história do touro Ferdinando, uma produzida em 1938 e outra, em 2017, por estúdios que atualmente pertencem a Disney². Ambos os filmes de animação foram baseados em A História de Ferdinando, uma literatura infantil de 1936 escrita pelo estadunidense Munro Leaf (1905-1976).

Seja na versão literária de Munro Leaf, seja nas versões animadas de 1938 e 2017, essas produções contam a história de Ferdinando, um touro espanhol, cuja personalidade possibilita debater sobre as marcações e transgressões que envolvem a (trans)formação do gênero. Nesse ponto, concordamos com Raewyn Connell e 


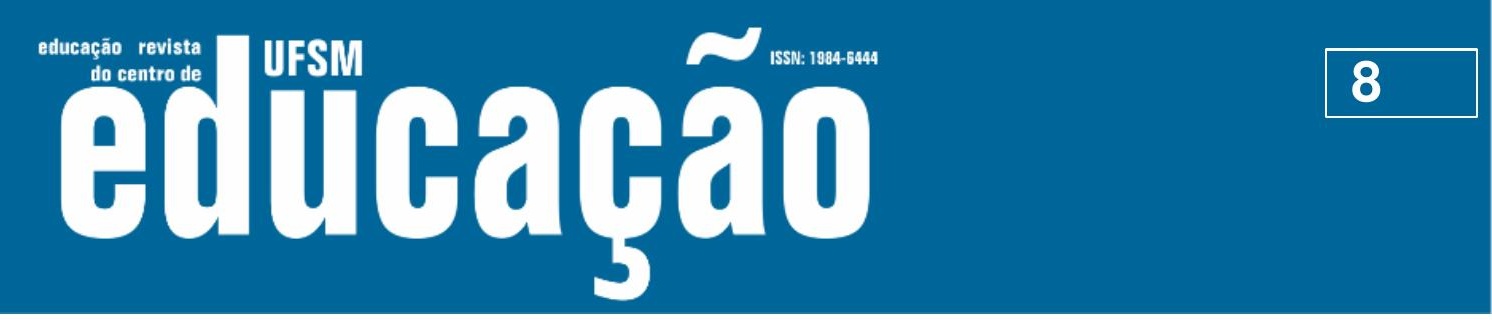

ISSN: 1984-6444 | http://dx.doi.org/10.5902/1984644435815

essencialista e naturalista ${ }^{3}$, Elisabeth Badinter (1993), Raewyn Connell ${ }^{4}$ (1995; 1997; 2016), Raewyn Connell e Rebecca Pearse (2015), Michael Kimmel (1998), Guacira Lopes Louro (1997; 2000; 2016), Fernando Herraiz García (2013), Luciana Borre Nunes e Raimundo Martins (2017), contribuem para que enxerguemos as masculinidades e feminilidades como expressões transitórias, construídas culturalmente e atravessadas relações de poder.

\section{As masculinidades defendidas e negociadas por Ferdinando}

Em comum, ambas as versões da história de Ferdinando revelam-nos que o personagem protagonista não consegue corresponder às marcações de gênero que a sociedade cobra aos sujeitos masculinos. As duas animações dão indicativos visuais e discursivos de que, desde a infância, Ferdinando fora um touro diferente dos demais. Enquanto os outros filhotes são representados agitados, pulando e trocando cabeçadas - como sinal da agressividade e da valentia que culturalmente são atribuídas a esse animal e às identidades de gênero masculinas- , Ferdinando é dócil e gentil e prefere repousar à sombra das árvores e deleitar-se com o voo das borboletas e com o perfume das flores. Na Figura 1, reunimos imagens de Ferdinando, referentes às versões de 1938 e 2017, respectivamente.

Figura 1 - Duas versões de Ferdinando
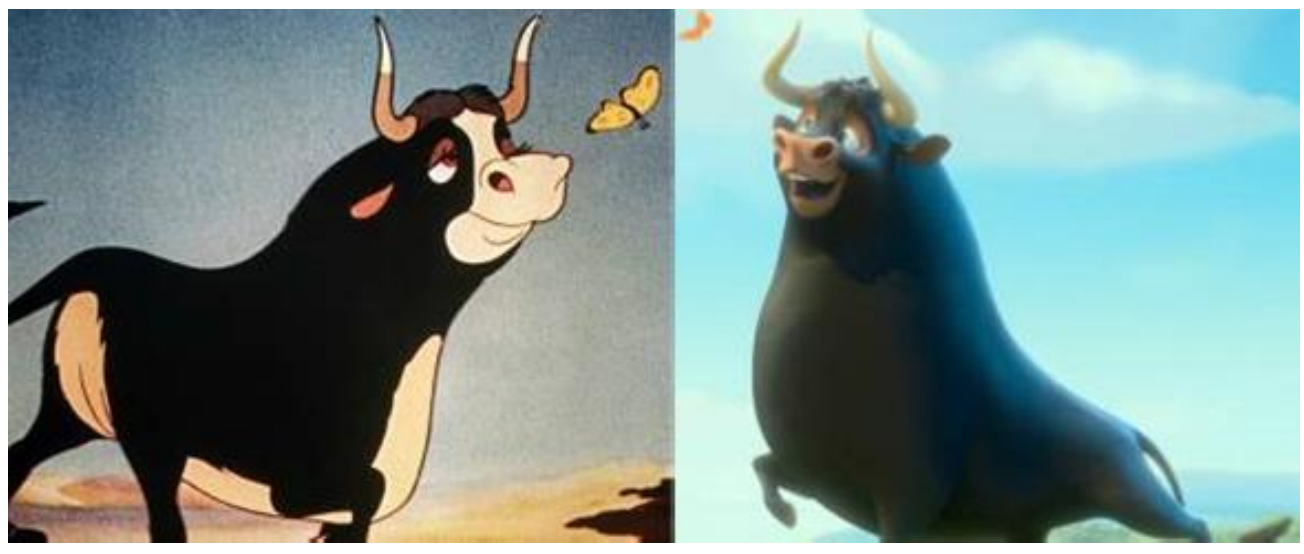

Fonte: Ferdinando, o touro (1938) e O touro Ferdinando (2017). 


\section{N

ISSN: 1984-6444 | http://dx.doi.org/10.5902/1984644435815

As perseguições e chacotas que marcam a infância de Ferdinando podem ser tomadas como analogia às agressões verbais, físicas e psicológicas conferidas aos meninos e meninas que não querem e/ou não conseguem responder aos ideais de masculinidade e feminilidade valorizados pelas escolas, mídias, religiões e demais instituições sociais. No que tange especificamente aos contextos escolares, Louro (1997) afirma que desde muito cedo, meninos e meninas aprendem a conferir apelidos, piadas e agressões àqueles e àquelas que não se harmonizam com as identidades de gênero tidas como "padrões". Praticar esportes e ter um bom desempenho nas aulas de educação física, por exemplo, são, segundo a autora, ideais de masculinidade constantemente tomados como "naturais" entre os meninos e a partir dos quais mobilizam-se exclusões. Por parte dos estudantes meninos, há, como analisam Nunes e Martins (2017) a necessidade de mostrarem-se homens por meio de um conjunto de atitudes expressadas em salas e corredores escolares.

\footnotetext{
Dentre essas atitudes, demonstrar que gostam ou que se sentem atraídos por meninas, brincar com jogos tipicamente masculinos repudiando o que pode ser considerado feminino, fazer constantes piadinhas contra gays, colocar apelidos pejorativos nas/os colegas que apresentam sexualidade "duvidosa", não permitir que sua heterossexualidade seja questionada, são predominantes. (NUNES E MARTINS, 2017, p. 61).
}

As pedagogias culturais produzidas nos contextos escolares também são evidenciadas por Herraiz García (2013). Em um estudo autoetnográfico, que exigiu (re)visitar desenhos, anotações e memórias de suas experiências escolares, o autor investiga as maneiras como a escola e especificamente a educação artística lhe proporcionaram referências para a construção de masculinidades. Esse processo de pesquisa conduziu o autor a reflexão de que,

os homens não tinham por que ser mais fortes que as mulheres, nem estavam mais adestrados para determinados trabalhos, nem deviam ser líderes nos diferentes espaços em que se moviam, nem tinham que ocultar sua vida emocional, etc. Refletir sobre isso me levou a encontrar os limites normativos que pautavam socialmente o que era permitido fazer e desfazer entre meus iguais, do mesmo modo que aprendi a silenciar e a calar aquilo que me colocava em situação de desprestígio social. (HERRAIZ GARCÍA, 2013, p.183). 


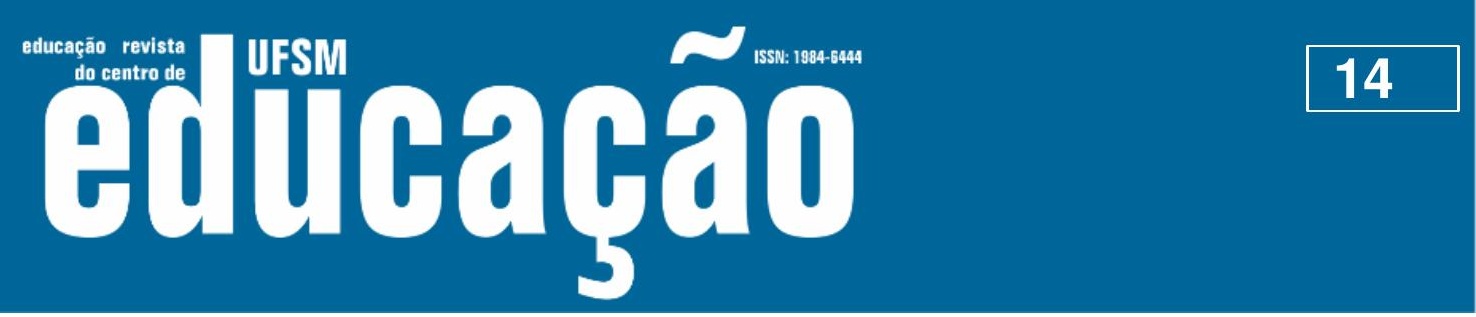

ISSN: 1984-6444 | http://dx.doi.org/10.5902/1984644435815

Em um dado recorte de O Touro Ferdinando (2017), o protagonista também parece se permitir viver sua masculinidade, sem cobrar-se por ser forte, por ser líder e muito menos por ocultar seus sentimentos. Quando ele foge da fazenda e é acolhido por Nina e seu pai - uma família de floristas que admira e valoriza a amabilidade do protagonista - a masculinidade de Ferdinando deixa de ser ajustada ao modelo forte, agressivo e corajoso. Ao som da música Home ${ }^{5}$, a transição de Ferdinando para a vida adulta mostra que, tendo sido amparado por essa família, o touro manteve sua personalidade doce e branda, apesar da força e peso que seu corpo passou a deter. Enquanto a letra da música diz que "Sempre fora de lugar, eu sabia que precisava de algo novo para mim", Ferdinando é representado com sua nova família. A sequência de imagens mostra Ferdinando rolando no gramado, interagindo com flores e borboletas, experimentando penteados, dançando flamenco, trocando afetos e auxiliando no transporte das flores, como destacamos na Figura 5 - o que sinaliza que naquele contexto, sua masculinidade não é considerada estranha.

Figura 5 - A nova família de Ferdinando

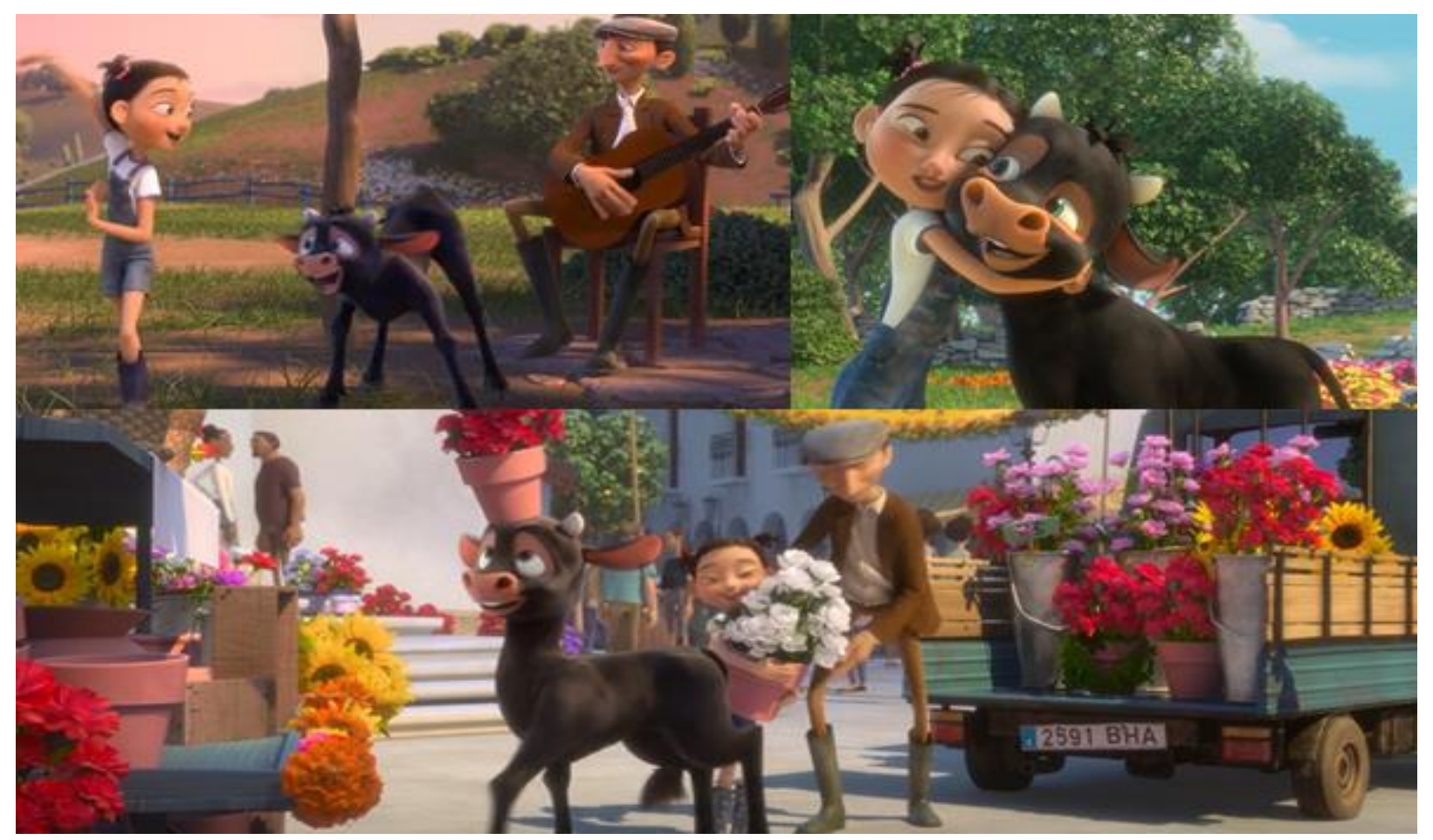

Fonte: O touro Ferdinando (2017).

Educação | Santa Maria | v. 45 |2020

Disponível em: https://periodicos.ufsm.br/reveducacao 


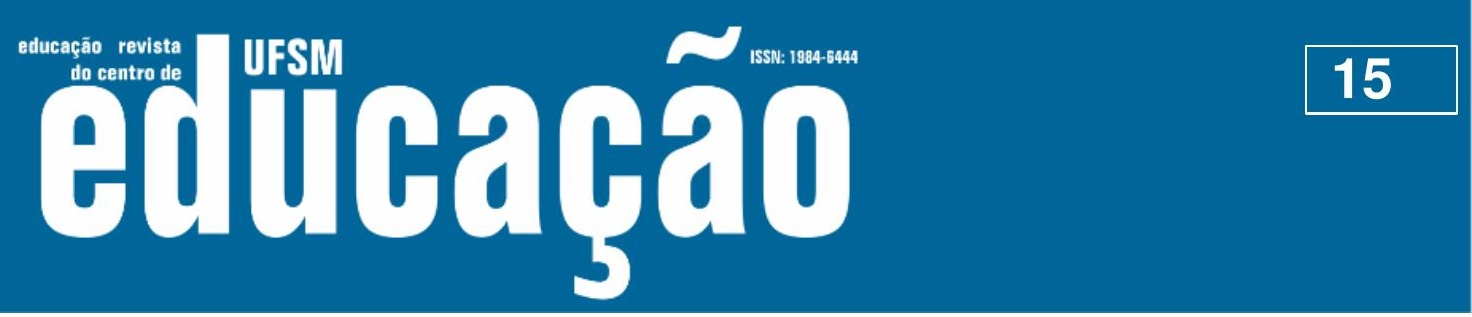

ISSN: 1984-6444 | http://dx.doi.org/10.5902/1984644435815

O processo de inscrição de masculinidades e feminilidades nos corpos, conforme explica Louro (2000), é sempre feito em contextos culturais, portanto, responde e expressa valores dessa mesma cultura. Assim, masculinidades e feminilidades são avaliadas como normais ou estranhas segundo os critérios de normalidade e de estranheza de cada sociedade.

Masculinidade Hegemônica, Masculinidade Cúmplice e Masculinidade Subordinada são, segundo Connell (1995; 1997; 2016), algumas das identidades a partir das quais sujeitos disputam poder e representatividade nas Políticas da Masculinidade. Em análise da caracterização de Valente, Guapo, Angus, Magrão e Máquina (Figura 6) - personagens coadjuvantes de O touro Ferdinando (2017) - e dos papéis que eles ocupam na história, é possível aproximá-los dos conceitos elaborados pela autora.

Figura 6 - Políticas da Masculinidade e os personagens Valente, Guapo, Angus, Magrão e Máquina.

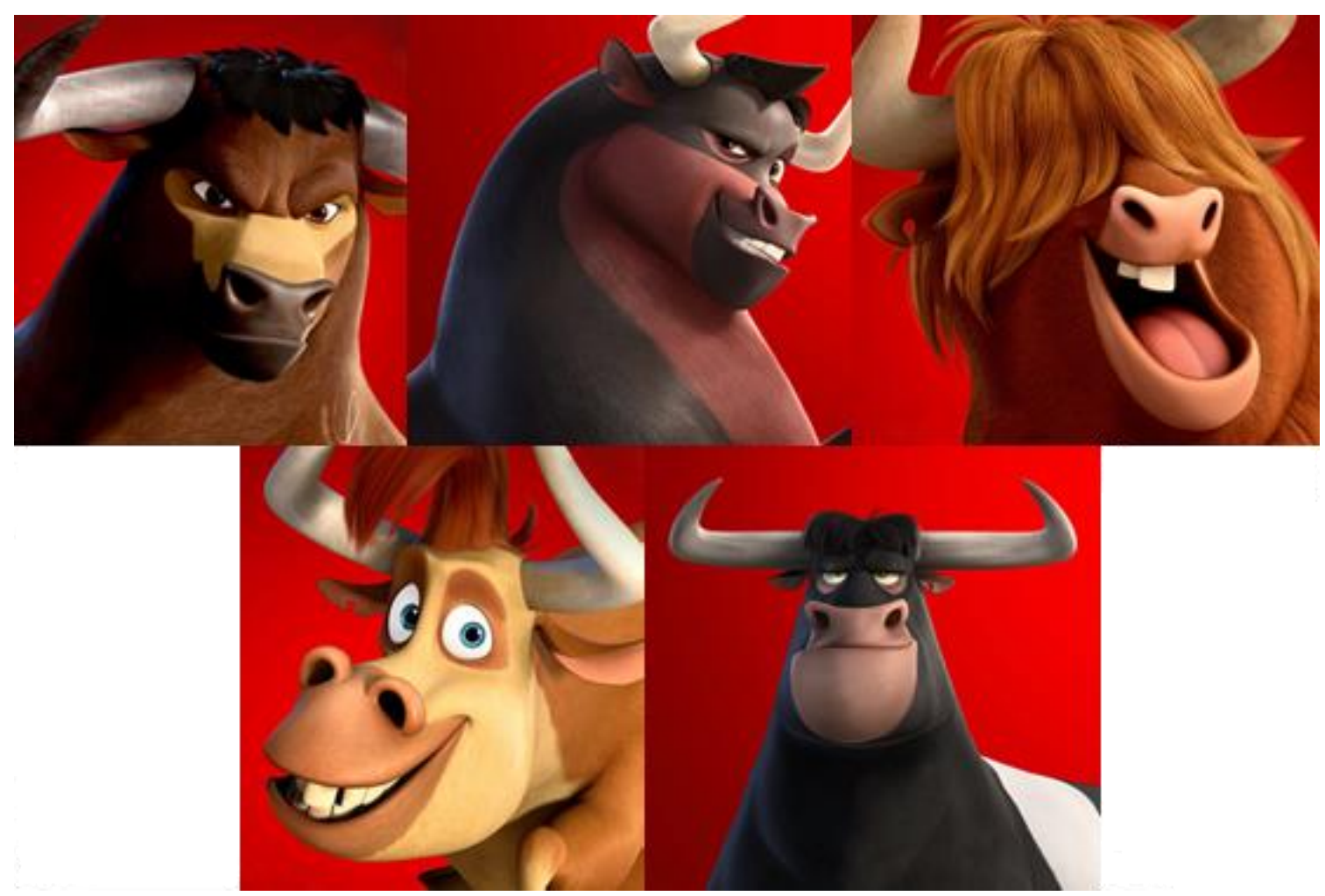

Fonte: http://ferdinandmovie.wikia.com/wiki/Ferdinand_Wiki. Acesso em 26 de mai. de 2018. 


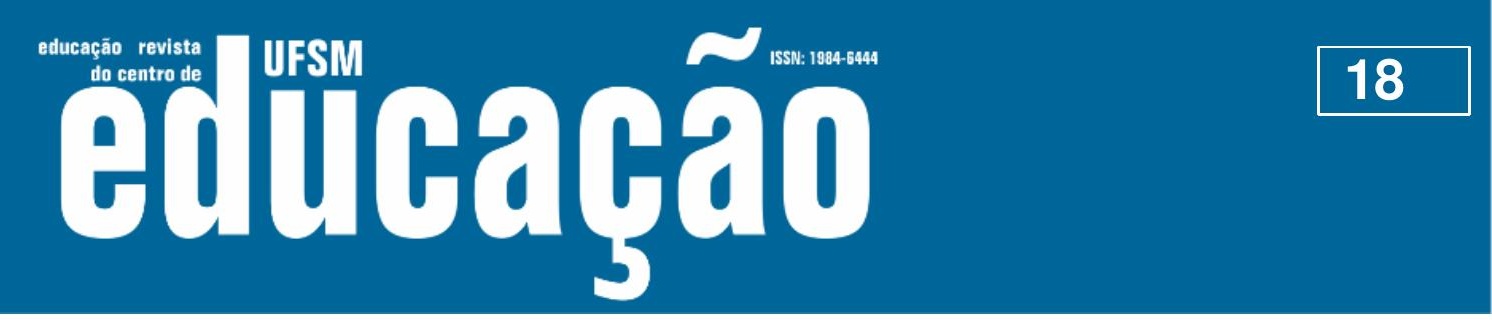

ISSN: 1984-6444 | http://dx.doi.org/10.5902/1984644435815

No curta-metragem, Ferdinando corre, destrói paredes, derruba uma árvore e provoca medo nos demais touros não para se exibir, mas sim, porque fora picado por uma abelha. No longa-metragem, por sua vez, Ferdinando é agredido por Valente e pressionado a lutar contra ele. Após pedir sucessivas vezes para que Valente pare de o atacar, para se defender, o protagonista acaba por quebrar um dos chifres de seu oponente, acidentalmente, como evidenciado na Figura 7.

Figura 7 - Ferdinando reagindo à picada da abelha, e Ferdinando evitando lutar contra Valente

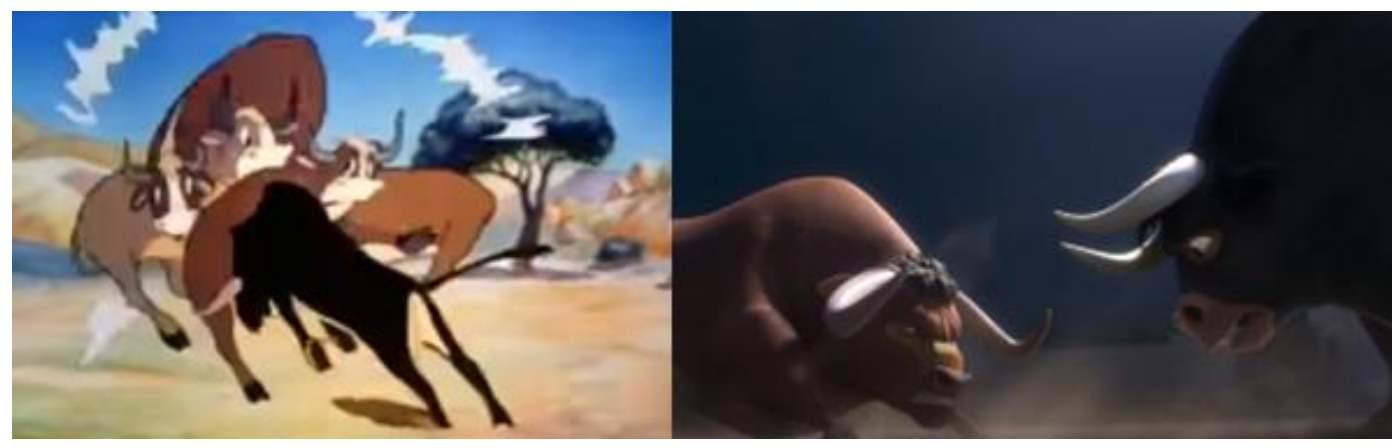

Fonte: Ferdinando, o touro (1938) e O touro Ferdinando (2017).

Dessas cenas podemos interpretar, primeiro, que os sujeitos podem oscilar entre Masculinidades Subordinada e Hegemônica - como fez Ferdinando - e, segundo, que o protagonista só foi aprovado pelos toureiros a partir do momento que seus gestos gentis e passivos foram ofuscados pela agressividade e força identificadas em seu corpo.

Além de as Políticas da Masculinidade (Connell, 1995; 1997; 2016) contemplarem que um mesmo sujeito possa desempenhar diferentes masculinidades, reiteram que uma mesma expressão de masculinidade pode ser lida e valorizada/desvalorizada de formas distintas conforme o contexto em que se manifesta. Em O touro Ferdinando (2017), essa ambivalência de leitura ocorre pelo menos três vezes, quando a gentileza e passividade de Ferdinando se tornam expressões da Masculinidade Hegemônica: 1) quando ele é acolhido pela família de floristas; 2) à medida que ele passa a ser imitado e seguido pelos demais touros, como quando ocupam a cidade e entram em um ônibus; 3) e quando a Masculinidade Hegemônica de Valente é desequilibrada após ele perder um de seus chifres em uma batalha (Figura 8). 


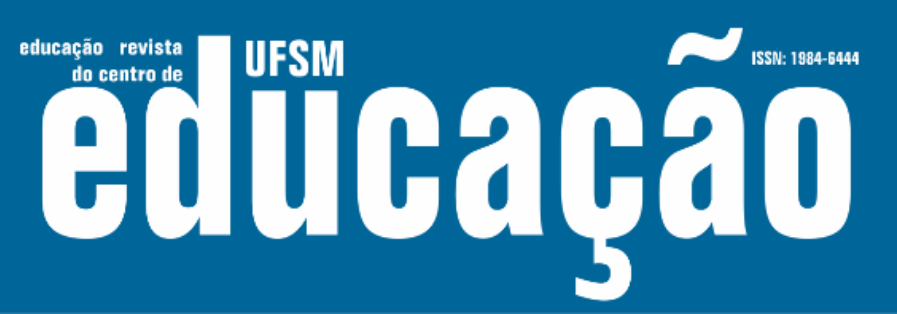

ISSN: 1984-6444 | http://dx.doi.org/10.5902/1984644435815

Figura 8 - Dinâmica das Políticas da Masculinidade em Ferdinando e Valente

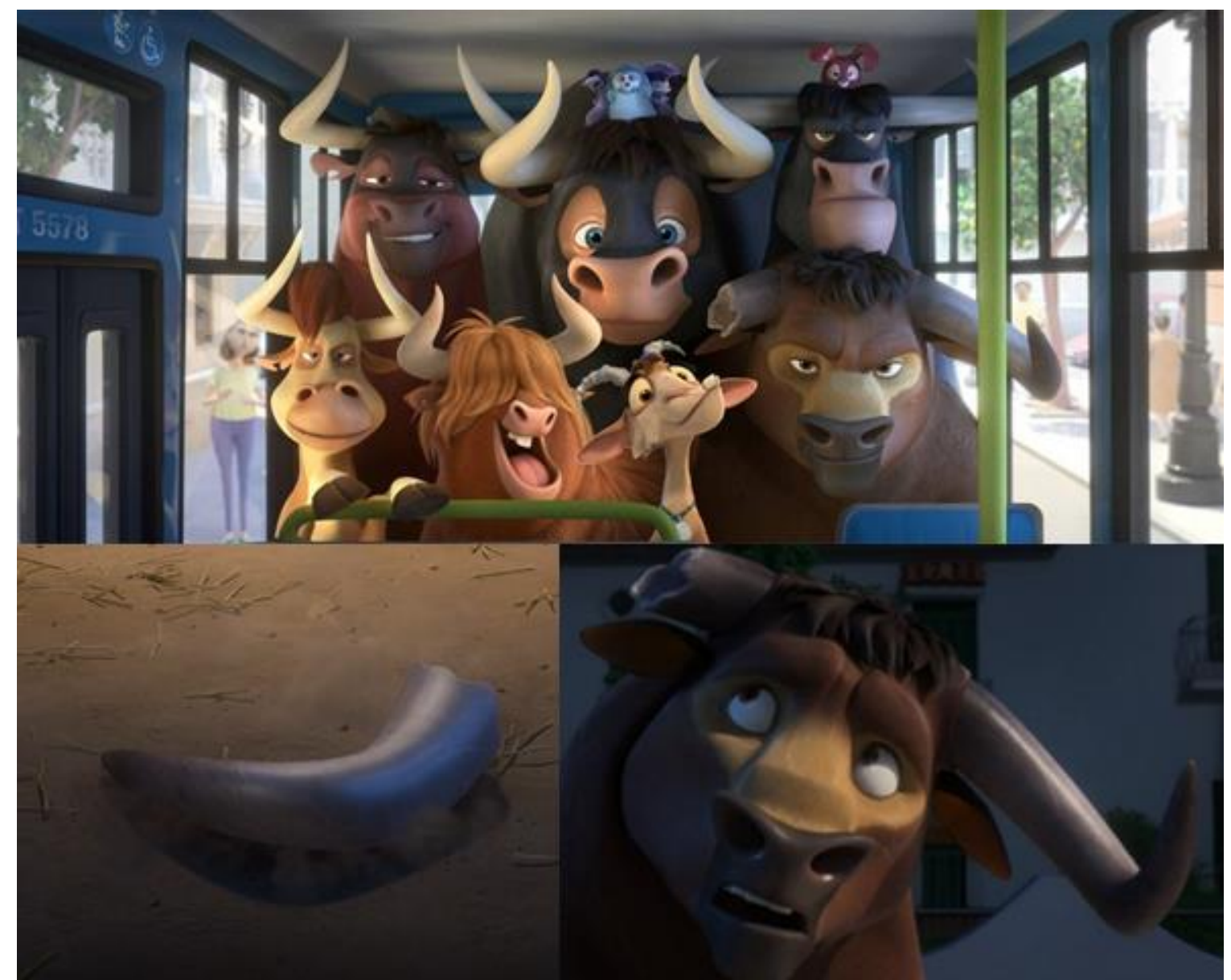

Fonte: O touro Ferdinando (2017).

Especificamente sobre esse terceiro episódio, consideramos que a carga simbólica e o formato fálico do chifre de Valente podem ser aproximados do pênis, como uma espécie de "distintivo" da masculinidade. Relacionamos essa análise à consideração de Badinter (1993, p. 169, tradução nossa) de que, numa sociedade patriarcal, "qualquer dificuldade [que o homem possa ter] com seu pênis é motivo de profunda humilhação e desespero, já que implica a perda de sua virilidade". Assim, se tomamos o chifre como elemento fálico análogo ao pênis, o acidente de Valente e o fato de após isso o coadjuvante ter sido encaminhado para um matadouro podem simbolizar o desequilíbrio de sua virilidade. Além do mais, ajudam a explicar os porquês de ele, dali por diante, passar a assumir comportamentos mais tolerantes e menos violentos. 


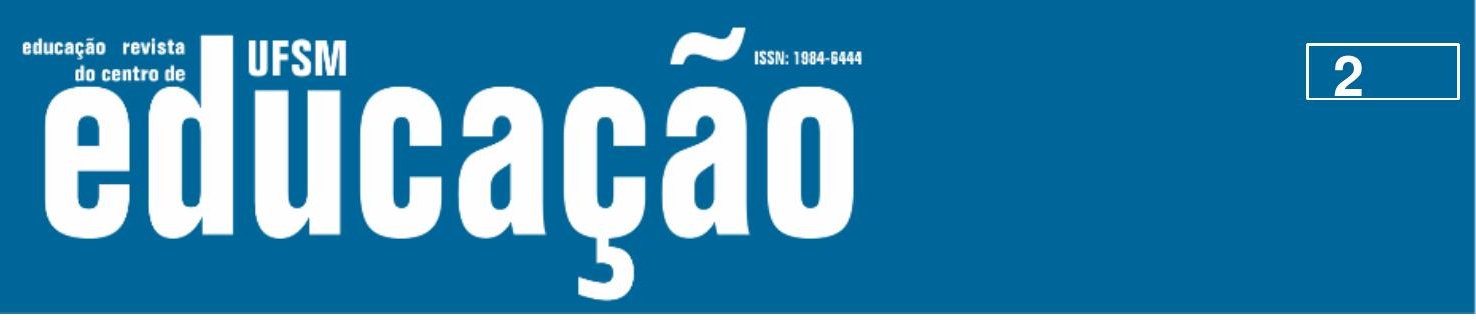

ISSN: 1984-6444 | http://dx.doi.org/10.5902/1984644435815

Figura 10 - O desfecho de $O$ touro Ferdinando

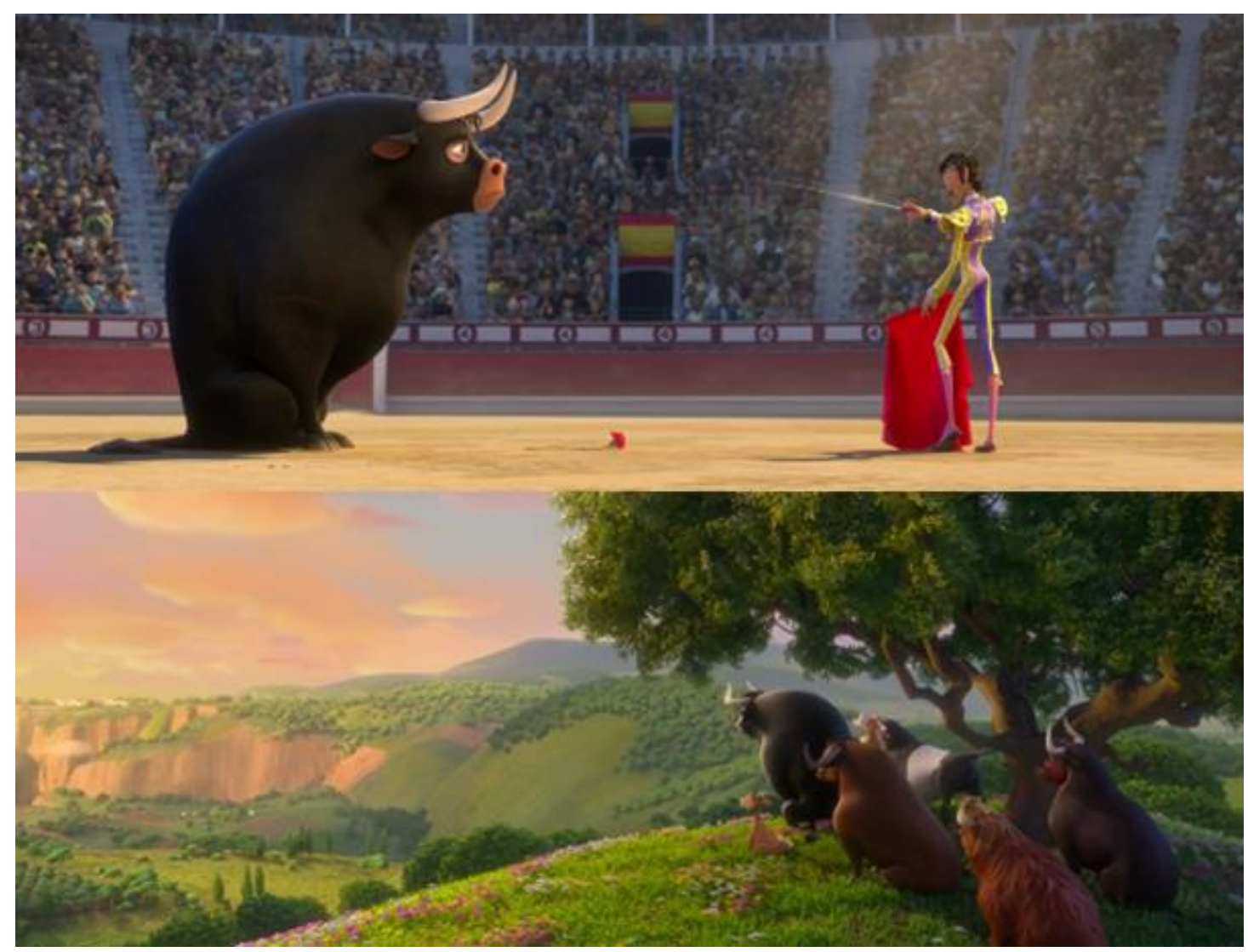

Fonte: O touro Ferdinando (2017).

Vale observar que, apesar de o desfecho do longa-metragem possibilitar ao público identificações com heróis masculinos não necessariamente agressivos e viris, suas pedagogias culturais ainda conferem adjetivos pejorativos e abjetos a outros sujeitos que se desviam (talvez mais drasticamente) das normas esperadas, conforme a identidade de gênero que Ihes foram atribuídas. Referimo-nos, precisamente, aos cavalos Hans e Klaus. Mesmo apresentando identidades de gênero masculinas, esses personagens são caracterizados com significantes femininos - como as crinas que se movimentam semelhante a cabelos longos, os gestos leves, as vozes agudas e os saltos e rodopios sincronizados (Figura 11). 


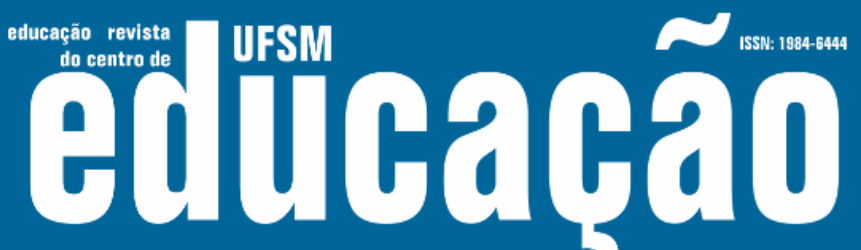

ISSN: 1984-6444 | http://dx.doi.org/10.5902/1984644435815

percebemos que as falas e os movimentos de Hans e Klaus proporcionavam gargalhadas ao público. Nessa mesma ocasião ainda, durante a sessão, ouvimos na plateia, uma voz feminina e adulta comentar com uma criança em tom de deboche: "são cavalos gays". Desta forma, por serem afeminados e associados ao risível, os personagens cavalos podem exemplificar a consideração de Louro $(2016,68-69)$ de que, apesar das conquistas e visibilidades já alcançadas, sob a lógica patriarcal, "paradoxalmente, esses sujeitos 'marginalizados' continuam necessários, já que servem para circunscrever os contornos daqueles que são normais e que, de fato, se constituem os sujeitos que importam".

\section{Considerações Finais}

O conceito de pedagogias culturais contribui para problematizar os artefatos do cotidiano e para que seus significados sejam identificando e analisando em contextos escolares e acadêmicos. Em consonância com os Estudos Culturais, esse conceito também sublinha o poder e a carga simbólica que constituem as imagens, sons, texturas e discursos do cotidiano, sem desconsiderar a performatividade que os sujeitos desempenham em processos de identificação e negação daquilo que lhes é apresentado.

Especificamente nesse estudo, questionamo-nos: Quais significados acerca de masculinidades são produzidos, ensinados e compartilhados por filmes de animação? Em análise das animações Ferdinando, o touro (1938) e O touro Ferdinando (2017), formulamos algumas respostas que nos instigam a perceber os investimentos visuais, sonoros e discursivos para que determinadas masculinidades e feminilidades sejam aceitas e outras não. Nos dois filmes de animação que analisamos, identificamos pedagogias culturais semelhantes no que tange, primeiro, à não-correspondência do personagem Ferdinando ao ideal hegemônico de masculinidade, e segundo, às instruções e correções que o protagonista é submetido por expressar uma identidade de gênero masculina tida "desviante".

Essas semelhanças discursivas mostram que, mesmo diante dos 79 anos que separam a produção do curta-metragem da produção do longa, entre sujeitos de um 


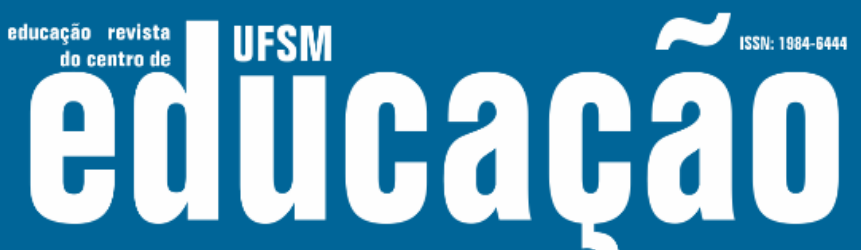

ISSN: 1984-6444 | http://dx.doi.org/10.5902/1984644435815

mesmo grupo, há investimentos e disputas para que o modelo da Masculinidade Hegemônica seja seguido e não "profanado" com elementos socialmente lidos como femininos. Tanto na versão de 1938 quanto na de 2017, o protagonista é instruído por familiares a (re)calibrar seus gestos, pensamentos e preferências. A pressão exercida pela mãe e pelo pai de Ferdinando foram tomadas por nós como exemplo de que as cobranças do pertencimento aos padrões de gênero se iniciam já nesse primeiro âmbito social, sendo a família a primeira instituição reguladora das condutas de gênero.

A relação de Ferdinando com os demais animais, por sua vez, indica que a regulação de gênero e, mais especificamente, as Políticas da Masculinidade, prolongam-se em níveis distintos 3 em outros espaço e círculos sociais, tais como a amizade, a rivalidade, o esporte, o lazer e o trabalho. Como touro, Ferdinando é impelido a demonstrar agressividade e força para se sentir pertencente e autorizado pelo grupo de animais e também para ser valorizado entre os personagens humanos. As hierarquias, submissões e disputas que perpassam as relações entre Ferdinando, os demais touros e os toureiros podem ser tomadas como análogas aos ajustes que, na vida real, são conferidos às identidades masculinas e femininas.

$\mathrm{Na}$ presença de outros sujeitos, as identidades de gênero de meninos e meninas, homens e mulheres, tornam-se vigiadas para que determinadas características sejam reclamadas e outras censuradas. Em Ferdinando, o touro (1938) e O touro Ferdinando (2017) identificamos assimetrias entre os comportamentos que os touros exercem quando estão sozinhos, quando estão em grupo e também quando estão sendo observados. Nesse último ponto, especificamente, reivindicam-lhes que demonstrem violência, força e competitividade e que corrijam suas fraquezas.

Apesar das pressões exercidas pelos coadjuvantes para que o protagonista respeite as inscrições de gênero valorizadas naqueles contextos, nas duas narrativas fílmicas, Ferdinando transgride com aquilo que the é esperado enquanto "macho" e também enquanto "touro". Nesse ponto, a expressão "macho como um touro" utilizada nas conversas cotidianas e no senso comum para autorizar determinada 


\section{工 Tism Eutlatato

ISSN: 1984-6444 | http://dx.doi.org/10.5902/1984644435815

convivem diariamente. Além disso, imagens e personagens semelhantes a esses atravessam os contextos escolares, quer seja por meio de ações e ambientações apresentadas pela própria instituição, quer seja por meio do acesso pessoal que as crianças fazem a essas referências quando, por exemplo, compartilham imagens, fotos, materiais escolares e preferências. Desta forma, pedagogias culturais podem ser tomadas como um conceito que, no âmbito educacional, favorece que os elementos apresentados pelos filmes e demais artefatos culturais sejam questionados e debatidos para além do prazer que proporcionam.

\section{Corpus de análise}

FERDINANDO, o touro. Direção: Dick Rickard. Produção: Walt Disney Productions. 1938. Disponível em: https://www.youtube.com/watch?v=B3qO8ZM7lkl\&t=5s. Acesso em 25 de mai. de 2018. son., color. Dublado. Port.

O TOURO Ferdinando. Direção: Carlos Saldanha. Produção: Twentieth Century Fox. 2017. 1 DVD (108 min.), son., color. Legendado. Port.

\section{Referências}

ANDRADE, Paula Deporte. A invenção das Pedagogias Culturais. In: CAMOZZATO, Viviane Castro; CARVALHO, Rodrigo Saballa de; ANDRADE, Paula Deporte de (orgs.). Pedagogias Culturais: a arte de produzir modos de ser e viver na contemporaneidade. Curitiba: Appris, 2016, p. 19-32.

ANDRADE, Paula Deporte; COSTA, Marisa Vorraber. Nos rastros do conceito de pedagogias culturais-invenção, disseminação e usos. Educação em Revista, Belo Horizonte, n.33, 2017, p. 1-23. Disponível em http://www.scielo.br/pdf/edur/v33/19826621-edur-33-e157950.pdf. Acesso em 25 de mai. de 2018.

BADINTER, Elisabeth. $X Y$, la identidad masculina. Madrid: Alianza Editorial, 1993. $254 p$.

BALISCEI, João Paulo. Vilões, heróis e coadjuvantes: um estudo sobre Masculinidades, Ensino de Arte e Pedagogias Disney. Tese (Doutorado). Pósgraduação em Educação, Universidade Estadual de Maringá. Maringá, 2018. 260 p. 


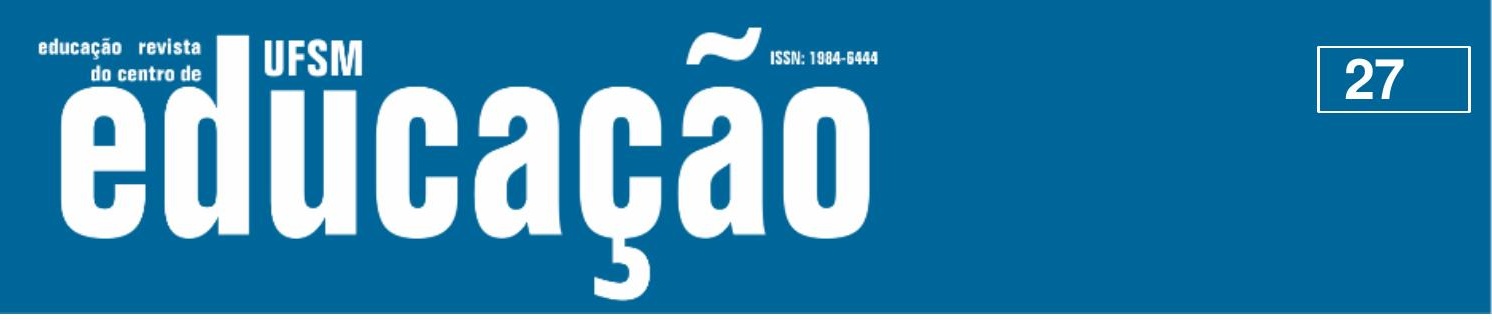

ISSN: 1984-6444 | http://dx.doi.org/10.5902/1984644435815

BALISCEI, João Paulo; ACCORSI, Fernanda Amorim; TERUYA, Teresa Kazuko. Problematizando "Toda forma de amor": a visibilidade de grupos minoritários na publicidade de O Boticário. Revista Educação Unisinos, São Leopoldo, v.21, n.1, p. 111-121, jan./abr. 2017. Disponível em http://revistas.unisinos.br/index.php/educacao/article/view/edu.2017.211.12/5859. Acesso em 21 de abr. de 2017.

BALISCEI, João Paulo; CALSA, Geiva Carolina; STEIN, Vinícius. "(In)felizes para sempre"? Imagens da Disney e a manutenção da heteronormatividade. Revista Bagoas: estudos gays, gênero e sexualidades, Natal, v.10, n.14, p. 163-180, jan./jun. de 2016b. Disponível em https://periodicos.ufrn.br/bagoas/article/view/11451. Acesso em 03 de mar. de 2017

BALISCEI, João Paulo; MAIO, Eliane Rose; CALSA, Geiva Carolina. Um ovo azul e outro rosa: Pedagogia Kinder e a construção visual dos gêneros e das infâncias.

Revista Visualidades, Goiânia, v.14, n. 1, p.284-315, jan./jun., 2016. Disponível em https://www.revistas.ufg.br/VISUAL/article/view/36655/21584. Acesso em 01 de set. de 2016.

CONNELL, Raewyn. Gênero em termos reais. São Paulo: nVersos, 2016. 272p.

CONNELL, Raewyn; PEARSE, Rebecca. Gênero: uma perspectiva global. São Paulo: nVersos, 2015. 335p.

CONNELL, Robert W. Políticas da masculinidade. Revista Educação \& Realidade, Porto Alegre, v.20, n.2, 1995, p.185-206.

CONNELL, Robert W. La organización social de la masculinidad. In: VALDÉS, Teresa; OLAVARRÍA, José (orgs.). Masculinidad/es. Santiago: FLACSO/ISIS Internacional, Ediciones de las Mujeres, 1997, p. 31-48.

CUNHA, Susana Rangel Vieira da. Imagens na Educação Infantil como Pedagogias Culturais. In: MARTINS, Raimundo; TOURINHO, Irene (orgs.). Pedagogias culturais. Santa Maria: Ed. Da UFSM, 2014, p.199-224.

FISCHER, Rosa Maria Bueno. O dispositivo pedagógico da mídia: modos de educar na (e pela) TV. Educação e pesquisa, São Paulo, v. 28, n. 1, 2002, p.151 - 162.

Disponível em http://www.revistas.usp.br/ep/article/view/27882/29654. Acesso em 24 de mai. de 2018.

GIROUX, Henry. El ratonzito feroz: Disney o el fin de la inocencia. Madrid:

Fundación Germán Sánchez Ruipérez, 2001. 


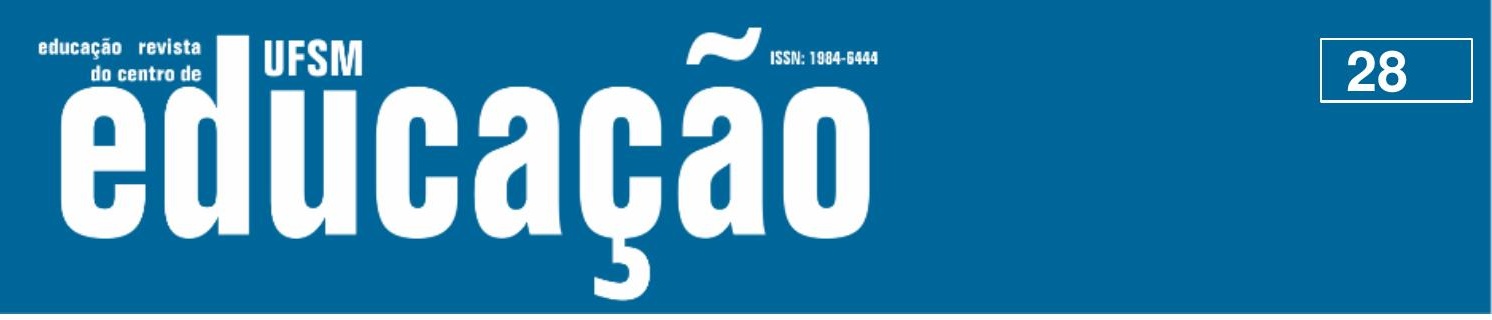

ISSN: 1984-6444 | http://dx.doi.org/10.5902/1984644435815

GOMES, Lisandra Ogg. O cotidiano, as crianças, suas infâncias e a mídia: imagens concatenadas, Pro-Posições, São Paulo, v. 19, n. 3, 2008, p. 175-193. Disponível em http://www.scielo.br/pdf/pp/v19n3/v19n3a09.pdf. Acesso em 25 de mai. de 2018.

HALL, Stuart. A identidade cultural na pós-modernidade. Rio de Janeiro: DP\&A, 2006.

HALL, Stuart. Quem precisa da identidade?. In: SILVA, Tomaz Tadeu da (org.). Identidade e diferença: a perspectiva dos estudos culturais. Petrópolis, RJ: Vozes, 2012, p. 103-133.

HALL, Stuart. Cultura e representação. Rio de Janeiro: Editora PUC-Rio, 2016. 259 p.

HERRAIZ GARCÍA, Fernando. Uma aproximação à pesquisa autoetnográfica: algumas questões para continuar aprendendo. In: MARTINS, Raimundo; TOURINHO, Irene (orgs.). Processos e práticas de pesquisa em cultura visual e educação. Santa Maria: Ed. da UFSM, 2013, p.273-289.

KINCHELOE, L. Joe. McDonald's, poder e criança: Ronald McDonald (também conhecido como Ray Kroc) faz tudo por você. In: Cultura infantil: a construção corporativa da infância. Shirley R. Steinberg, Joe L. Kincheloe (orgs.). Rio de Janeiro: Civilização Brasileira, 2001, p. 385-412.

LOURO, Guacira Lopes. Gênero, sexualidade e educação. Uma perspectiva pósestruturalista. Petrópolis: Vozes, 1997. 179p.

LOURO, Guacira Lopes. Pedagogias da Sexualidade. In: LOURO, Guacira Lopes (org.). O corpo educado: pedagogias da sexualidade. Belo Horizonte: Autêntica, 2000, p.7-34.

LOURO, Guacira Lopes. Um corpo estranho: ensaios sobre sexualidade e teoria queer. Belo Horizonte: Autêntica, 2016. 96p.

NUNES, Luciana Borre. As Imagens que Invadem as Salas de Aula: Reflexões sobre Cultura Visual. São Paulo: Ideias \& Letras, 2010.

NUNES, Luciana Borre; MARTINS, Raimundo. Cultura Visual: tramando gênero e sexualidades nas escolas. Recife: Editora UFPE, 2017. 244p. Disponível em https://issuu.com/lucianaborre/docs/cultura_visual_tramando_genero_e_se. Acesso em 12 de dez. de 2017.

SABAT, Ruth. Filmes infantis e a produção performativa da heterossexualidade. Tese (Doutorado). Pós-graduação em Educação, Universidade Federal do Rio Grande do Sul. Porto Alegre, 2003. 185p. 


\section{usm Eltothato

ISSN: 1984-6444 | http://dx.doi.org/10.5902/1984644435815

STEINBERG, Shirley. A mimada que tem tudo. In: Cultura infantil: a construção corporativa da infância. Shirley R. Steinberg, Joe L. Kincheloe (orgs.). Rio de Janeiro: Civilização Brasileira, 2001, p. 321-338.

VIANNA, Maria Letícia Rauen. Desenhando com todos os lados do cérebro: possibilidades para transformação das imagens escolares. Curitiba: Ibpex, 2010. 207p.

\section{Correspondência}

João Paulo Baliscei - Rua Quintino Bocaiúva, 935, apto 502, Zona 07, CEP 87020 160, Maringá, Paraná, Brasil.

\section{Notas}

${ }^{1}$ Nesse artigo, quando citamos uma autora ou autor pela primeira vez, optamos por mencionar seus nomes completos. Nas demais menções feitas ao decorrer do texto, identificamo-los/as apenas pelos sobrenomes.

${ }^{2}$ O Touro Ferdinando (2017) foi produzido pela 20th Century Fox, estúdio que em 2017 fora comprado pela Disney por cerca de US\$52,4 bilhões.

3 Perspectivas essencialista e naturalistas, conforme critica Badinter (1993), consideram que comportamentos e habilidades masculinas e femininas são inatos aos corpos, conforme o sexo dos sujeitos. Logo, nessa abordagem da qual nós e a autora nos distanciamos, gênero é tomado como efeito de propriedades biológicas e a violência e a competitividade, por exemplo, são consideradas expressões naturais dos sujeitos masculinos.

${ }^{4}$ Ainda que na autoria de um dos textos utilizados nesse estudo a identificação de Connell seja indicada por seu nome civil masculino - Robert William Connell -, em respeito à sua identidade de gênero, utilizamos pronomes e substantivos femininos para nos referirmos à autora, uma mulher transexual, conhecida por Raewyn Connell.

${ }^{5}$ A letra completa da música de Nick Jonas, assim como sua tradução e o clipe original podem ser localizados no link: https://www.letras.mus.br/nick-jonas/home/traducao.html. Acesso em 26 de mai. de 2018.

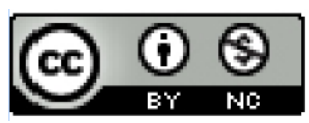

This work is licensed under a Creative Commons Attribution-NonCommercial 4.0 International (CC BY-NC 4.0) 